\title{
A Sala de Aula de Ciências: Uma Pesquisa Sobre as Práticas Curriculares em Uma Escola Pública de Belo Horizonte
}

\author{
Edna Gomes Roriz \\ Rita Amélia Teixeira Vilela \\ RESUMO
}

A pesquisa, na qual se baseia o presente texto, tem como objeto o estudo da sala de aula como espaço concreto de realização da educação escolar. A investigação busca reconstruir, de forma analítica, o processo pedagógico materializado pelo currículo e explicar como a dinâmica de entrelaçamento desses elementos se apresenta na escola. As questões de currículo sempre foram preocupações centrais da tradição crítica, pois exercem importante papel de, na relação educativa, estabelecer ligações entre saber, poder e identidade. A metodologia utilizada na pesquisa é denominada Hermenêutica Objetiva, tendo sido criada e desenvolvida pelo sociólogo alemão Ulrich Oevermann. Sua importância reside na possibilidade de, ao utilizála, reconstruir os sentidos dos elementos concretos do espaço "sala de aula". Essa metodologia está apoiada sobre os princípios da dialética negativa de Theodor Adorno, da hermenêutica sociológica e da sociologia estruturalista. Ao possibilitar que se confronte o aparente com o real, surgem as estruturas que dão sentido às práticas sociais. Assim, é possível identificar os desafios que surgem no processo educacional, para que mudanças, para melhoria desse processo, possam ser implantadas.

Palavras-chave: Currículo. Hermenêutica objetiva. Sala de aula.

Doutoranda

do Programa de

Pós-Graduação

em Educação

da Pontifícia

Universidade

Católica de Minas

Gerais. eroriz@

uol.com.br

- Doutora em

Educação pela

Universidade

de Frankfurt/

Alemanha,

professora

aposentada

da UFMG,

colaboradora do

PPGE/PUC Minas. 


\title{
INTRODUÇÃO
}

\begin{abstract}
Senhoras e Senhores,
Gostaria de anunciar agora o novo lema do meu governo. Ele é simples, é direto e é mobilizador. Reflete com clareza qual será a nossa grande prioridade e sinaliza para qual setor deve convergir o esforço de todas as áreas do governo. Nosso lema será: BRASIL, PÁTRIA EDUCADORA! Trata-se de lema com duplo significado. Ao bradarmos "BRASIL, PÁTRIA EDUCADORA" estamos dizendo que a educação será a prioridade das prioridades, mas também que devemos buscar, em todas as ações do governo, um sentido formador, uma prática cidadã, um compromisso de ética e um sentimento republicano. Só a educação liberta um povo e lhe abre as portas de um futuro próspero. Democratizar o conhecimento significa universalizar o acesso a um ensino de qualidade em todos os níveis - da creche à pós-graduação; significa também levar a todos os segmentos da população - dos mais marginalizados, aos negros, às mulheres e a todos os brasileiros a educação de qualidade. ${ }^{1}$
\end{abstract}

A sala de aula é considerada como um espaço, não apenas físico, mas social, cujas principais características podem ser identificadas a partir das relações que são nela estabelecidas pelos seus atores. Um espaço físico poderia ter sua existência assegurada independentemente de sua ocupação ou não, mas um espaço social deve ser construído em cada contexto histórico e, por isso, não oferece garantia de livre acesso àqueles que o desejam. De acordo com Novelli (1997), apesar de corresponder em espacialidade com outros espaços, a sala de aula apresenta singularidades advindas de sua ocupação. "Portanto, não basta a existência possível da sala de aula para que esta se torne sala de aula. [...] É precisamente a atividade desenvolvida em seu interior que a distingue de outros espaços. [...] sua atividade essencial extrapola limites físicos" (NOVELLI, 1997, p.44).

Pesquisar é uma das maneiras que temos de observar fenômenos e registrá-los para nosso conhecimento ou, até mesmo, buscar explicações para a sua compreensão. A pesquisa em sala de aula é uma das maneiras que temos de envolver seus frequentadores, propiciando que suas práticas sejam questionadas, que se estabeleça, caso necessário, uma correção de rumos, de compromissos e de intenções. Acreditamos que pesquisar a sala de aula para tentar compreender a escola e seus propósitos é sempre pertinente em qualquer tempo e, em especial, em um momento em que se pretende reforçar a razão de sua existência, tornando-a acessível e primando pela sua qualidade.

Nossa pesquisa tem como objeto o estudo da sala de aula como espaço concreto de realização da educação escolar. Buscamos reconstruir, através de dados empíricos,

\footnotetext{
${ }^{1}$ Informação extraída do discurso de posse da presidente Dilma Rousseff, proferido em 01 jan. 2015, no Congresso Nacional.
} 
o processo pedagógico materializado pelo currículo e, assim, explicar como se dá o entrelaçamento desses elementos no espaço chamado escola. De acordo com Silva (2006), não por coincidência, o currículo é também um dos elementos centrais das reestruturações e reformas educacionais, ocupando uma posição estratégica por ser o espaço onde se concentram e se desdobram as lutas em torno dos diferentes significados sobre o social e sobre o político. E, enquanto discurso, as políticas curriculares são elemento simbólico do projeto social dos grupos no poder.

\begin{abstract}
Essas políticas curriculares autorizam ou desautorizam grupos de especialistas, fabricam objetos epistemológicos, utilizando um jargão próprio, atribuindo papéis dentro da engrenagem escolar, gerando e movimentando toda uma indústria cultural criada em torno da escola, envolvendo textos, matrizes curriculares, normas e livros didáticos. Transformadas em currículo, as políticas curriculares têm efeitos na sala de aula, definindo papéis de professores e alunos e suas relações, legitimando os conhecimentos válidos e as formas de verificar sua aquisição, incluindo e excluindo saberes, estabelecendo diferenças, construindo hierarquias, entre tantos fatores de produção de identidades. (RORIZ, 2010, p.37).
\end{abstract}

Há, hoje, muitos estudos importantes no campo do currículo que procuram investigar questões da relação da escola com as diferentes dimensões do mundo exterior a ela. Entretanto, decidimos analisar a sala de aula e entendê-la através das relações que professores e alunos estabelecem não somente entre si, mas também entre o currículo prescrito e o real, optando por delimitar seu estudo no âmbito do processo pedagógico, pois esse corresponde à natureza da escola.

No campo do currículo, muitas investigações já foram realizadas, resultando em muitos trabalhos produzidos sobre os diversos temas relacionados com a escola, mas pouco foi feito no sentido de desvendar a sala de aula, utilizando uma metodologia de pesquisa que reconstruísse o sentido dos elementos concretos desse local. É esse, sem dúvida, o principal aspecto de nosso trabalho.

Metodologicamente, trabalhamos com a análise de protocolos de observação, preparados a partir de transcrições rigorosas e literais geradas a partir de gravações, em aúdio, de aulas de Ciências, do $9^{\circ}$ ano do Ensino Fundamental, ocorridas, no primeiro semestre de 2009, em uma escola pública da Rede Estadual de Ensino de Minas Gerais.

A metodologia que utilizamos é denominada de hermenêutica objetiva, desenvolvida, algumas vezes modificada, mas sempre defendida pelo seu criador, o sociólogo alemão Ulrich Oevermann (2002), em associação com outros investigadores que, na década de 1970, participaram, com ele, de pesquisas sociais na Alemanha. 
Os procedimentos da hermenêutica objetiva seguem, em especial, os princípios de sequencialidade e reconstrução, que determinam com que o texto seja analisado em sua estrutura temporal, permitindo análises específicas de suas pequenas partes que irão, em seguida, compor o texto resultante da análise. Essa forma de proceder permite que sejam apreendidos os conteúdos latentes que estão muitas vezes subjacentes ao que se vê e que se compreende mais facilmente, ou seja, os conteúdos manifestos. Dessa maneira, deixando que o texto nos revele o implícito, aquilo que está, frequentemente, oculto na sala de aula, podemos levantar os significados mais profundos das relações entre os atores que lá estiveram durante o processo que foi registrado, isto é, a aula.

Sem nenhuma dúvida, toda e qualquer investigação que pretenda interferir nas políticas curriculares, elevando a escola ao nível de importância esperado quando se quer transformá-la em espaço acessível e de excelência, deveria pautar-se por análises preliminares não superficiais. Em outras palavras, para mudar o que está estabelecido é necessário um olhar como aquele que paira sobre o desconhecido, que permita ver o que ainda não foi revelado e compreender aquilo que é, sem que pareça ser ou que se espera que seja. Para tal, a hermenêutica objetiva vale-se do método abdutivo, fundamentado por Charles S. Peirce (1980), no qual a busca e a verificação de hipóteses não é feita a priori, mas a cada passo da análise dos dados de pesquisa, qualquer hipótese que seja levantada deverá ser investigada a partir do caso concreto, para que sejam esclarecidos os fatos observados. O uso do método abdutivo permite que se descubra o novo, já que não se trata de verificar qualquer suposição ou ideia existente que poderia conduzir os rumos do processo investigativo.

Consideramos a reconstrução do sentido, como o objetivo epistemológico mais geral da sociologia interpretativa. Isto significa que a compreensão por excelência precede e constitui a base da investigação social. Este conceito de compreensão decorre da dúvida que, permanentemente, ronda o pesquisador, ou seja, será que as relações interpessoais e seus desdobramentos, envolvidos na convivência entre os indivíduos são sempre o que parecem ser?

O interesse cognitivo da hermenêutica objetiva centra-se em desvelar e compreender as estruturas latentes que estão ativas nas pessoas e que vão manifestarse em suas ações. A essas estruturas, Oevermann (1987) denomina de estruturas de significado. Desde a criação dessa metodologia e, mais tarde, no contexto de suas palestras, Oervermann tem sido veemente ao suscitar o debate sobre a diferença teórica mais fundamental no cerne da sociologia interpretativa, isto é, a discussão sobre a 
questão de onde o significado, em última análise, se constituiu.

De acordo com Hitzler (2005), considerando-se os ensinamentos da hermenêutica objetiva, as estruturas latentes de significado existem como a realidade social não-consciente de possibilidades de significado. Estas, não são apenas independentes das representações intencionais subjetivas conscientes, como tem sido demonstrado pelos observadores em suas sistemáticas, como também elas nem sequer precisam ser representadas psiquicamente em qualquer nível não-consciente. Ou seja, mesmo em protocolos, constituídos por textos preservados e que expressam as experiências de vida dos investigados, o objeto central de pesquisa da hermenêutica objetiva está, a priori, posto pelas normas das estruturas sociais que, por sua vez, são determinadas pela e para a sociedade humana.

Ao contrário de interpretações orientadas fenomenologicamente no sentido mais amplo, que são dirigidas a reconstruir o significado subjetivo normalmente destinado, a hermenêutica objetiva não considera os temas tratados nas relações entre as pessoas como sendo de relevante significado. Pelo contrário, constitucionalmente relevante são as estruturas que Oevermann assume como sendo objetivas, tanto as manifestas quanto as latentes.

O objetivo principal da hermenêutica objetiva não é o de trabalhar com interpretações individuais, mas, especialmente, com as estruturas latentes de significado que fundamentam as práticas sociais e seus significados subjetivos. Estas estruturas fornecem o contexto e o significado para a coordenação social das práticas. De acordo com Oevermann (2002), elas estão latentes, não se restringindo ao conhecimento discursivo dos atores e são independentes de suas intenções e significados subjetivos.

Os resultados que temos obtido em nossas investigações têm confirmado aquilo que o extenso estudo das teorias pedagógicas tem nos mostrado, isto é, desde o ideal de educação dos gregos, os processos envolvidos no ensino e na aprendizagem devem permitir que o educando tenha acesso ao conhecimento científico acumulado ao longo das gerações que o antecederam - a Instrução — valendo-se desses saberes como meio de prepará-lo para a vida social em sua comunidade - a Educação — e, assim, teríamos contribuído para a construção de um ser humano autônomo, preparado para lutar por uma sociedade mais justa na qual o respeito à diversidade, que caracteriza o ser humano, fosse uma constante e não uma exceção. Nesse momento, teríamos efetivado a Formação que nos leva à completude do tripé no qual dever-se-ia apoiar todo e qualquer processo desenvolvido no âmbito educacional. Ao longo de vários 
séculos, em diversas realidades sociais e os mais variados contextos históricos, a defesa da instituição escola só tem sentido se for para a realização dessa tríade, ou seja, utilizando-se da Instrução e da Educação para concretizar a Formação.

Nossas investigações revelaram que, na sala de aula, predomina o disciplinamento dos alunos por ação do professor, impedindo o educando de desenvolver a capacidade de tomar decisões. Na tentativa de cumprirem os prazos dados para que sejam desenvolvidos os conteúdos acadêmicos e assim cumprir um cronograma determinado pelas avaliações, o professor opta por treinar o aluno. Dessa forma, o limite do aprendizado passa a ser demarcado não pelo momento no qual a aprendizagem ocorreu, ou alimentado pela curiosidade do aluno, mas sim pelo que está prescrito como "conteúdo de prova". Desse modo, são evitadas as situações que incitariam o questionamento e o interesse em aprender. Prevalece, portanto, um ensino pela e para a heteronomia no lugar da autonomia. Com isso, a aula se transforma em um acontecimento cuja finalidade não é o ensino, mas o preparo para uma prova.

Embora haja momentos em que tanto o professor quanto os alunos se veem envolvidos e motivados pela vontade de ensinar e aprender apenas pelo conhecimento, concluímos que, infelizmente, esses momentos não são a regra, e sim a exceção. $\mathrm{Na}$ grande maioria das vezes, a preocupação dos alunos é saber se aquele conteúdo ensinado pelo professor será ou não conteúdo da prova. Desse modo, a lógica existente na sala de aula é a de que o aprendizado serve apenas para fazer provas, passar em um vestibular ou em outro concurso; não que essas habilidades não sejam importantes na vida social de um indivíduo, porém, o processo educacional não pode ser sustentado apenas por essa dimensão.

As aulas de Ciências foram, quase todas elas, exemplos da negação do conhecimento científico porque foram sustentadas basicamente no senso comum, sem a instauração do conhecimento e de procedimentos didáticos que possibilitassem o aprendizado. Nesse caso, a gravidade é maior, pois o livro didático utilizado pelos alunos encontrava-se repleto de erros conceituais.

Constatamos que os jovens estão submetidos a um conhecimento superficial, desenvolvido apenas para o cumprimento de tarefas. É possível que aí esteja a raiz do tão falado desinteresse dos jovens pela escola, em especial nos anos finais do Ensino Fundamental e durante todo o Ensino Médio. Entretanto, nossos resultados de pesquisa não confirmam que há desinteresse dos alunos pelo conhecimento, mas talvez pela forma como ele prevalece na instituição escolar.

De acordo com Adorno (2003), se o homem for levado a refletir sobre sua 
realidade, não aceitando as imposições da sociedade como naturais, ele poderia ser responsável pela sua própria realidade. Adorno e Horkheimer (1985), em seu livro Dialética do esclarecimento, afirma que o homem sempre foi um ser angustiado diante da insegurança sobre seu futuro, uma vez que, não podendo dominar a natureza, estaria à sua mercê, estando, além de subjugado a ela, podendo ser destruído por ela a qualquer momento. Acreditou-se que a Razão seria o instrumento que poderia levar o homem à condição de dominador da natureza, vencendo, assim, seu medo em relação a ela, pois uma explicação racional a respeito dos seus fenômenos seria a chave para o seu controle sobre ela. A questão é que a finalidade do esclarecimento, que seria a liberdade do ser humano, gerou uma nova dominação - a do homem pelo homem e sua técnica - dessa maneira, o processo educativo, pautado apenas na razão técnica não conduziu à autonomia e sim à heteronomia e à alienação. Em outras palavras, o fazer mecanizado impede a reflexão e, com isso, a tão sonhada libertação e, sem ela, o prazer torna-se objeto de falsas propagandas, de promessas ilusórias e, portanto, inacessíveis.

Ao estimular a competição como forma de sobrevivência e de progresso, muitas escolas consideram a competitividade como tema central do processo educativo, entendendo que, assim, aumentariam o preparo dos estudantes e a eficiência das instituições educacionais. Dessa forma, o sistema educacional perpetua a existência do dominador e dos dominados, fazendo com que prevaleça o instinto destrutivo que institucionaliza a violência. Por isso, a defesa da educação para autonomia romperia com a hierarquia criada pela competição na apropriação do conhecimento.

Com dificuldades em educar e instruir, a escola se vê em uma situação na qual ela abandonou a sua razão de existir, ou seja, propiciar a formação plena do indivíduo.

O currículo que foi materializado na sala de aula não possibilitou experiências formadoras capazes de elevar o sujeito ao uso da razão e reflexão para a construção de sua autonomia, possibilitando a existência de uma sociedade mais justa. O adestramento a que são submetidos os alunos pode ser um dos fatores que os desestimulariam a frequentar a escola. 


\section{REFERÊNCIAS}

ADORNO, Theodor W. Educação e emancipação. 3. ed. São Paulo: Paz e Terra, 2003.

ADORNO, Theodor W.; HORKHEIMER, M. Dialética do esclarecimento: fragmentos filosóficos. Rio de Janeiro: Jorge Zahar, 1985.

HITZLER, Ronald. The Reconstruction of Meaning. Notes on German Interpretive Sociology. Forum qualitative sozialforschung. Forum: Qualitative Social Research, v. 6, n. 3, Sep. 2005. Disponível em:

$<$ http://www.qualitativeresearch.net/index.php/fqs/article/view/7/16>. Acesso em: 30 jul.2015.

NOVELLI, Pedro G. A sala de aula como espaço de comunicação: reflexões em torno do tema. Interface, v. 1, n. 1, p. 43-50, 1997.

OEVERMANN, Ulrich. Klinische Soziologie auf der Basis der Methodologie der objektiven Hermeneutik: manifest der objektiv hermeneutischen Sozialforschung. [S. 1.]: IHSK, 2002.

OEVERMANN, U. Structures of meaning and objective Hermeneutics. In: VOLKER MEJA; DIETER MISGELD \& NICO STEHR (Org.) Modern german sociology. (european perspectives: a series in social thought and cultural criticism). New York: Columbia University Press, p. 436-447, 1987-1994

PIERCE, Charles S. Os Pensadores Charles Sanders Pierce. tradução de Armando Mora D'Olibeira e Sérgio Pomerangblum, 2a ed., São Paulo, Abril Cultural, 1980

RORIZ, Edna Gomes. O currículo e a sala de aula: desafios da escola contemporânea revelados através de aulas de ciências. 2010. 226 f. Dissertação (Mestrado) - rograma de Pós-Graduação em Educação, Pontifícia Universidade Católica de Minas Gerais, Belo Horizonte, 2010.

SILVA, Tomaz Tadeu. O currículo como fetiche: a poética e a política do texto curricular. Belo Horizonte: Autêntica, 2006. 